\title{
Focal lymphoid aggregates (nodules) in bone marrow biopsies: differentiation between benign hyperplasia and malignant lymphoma - a practical guideline
}

\author{
J Thiele, T K Zirbes, H M Kvasnicka, R Fischer
}

\begin{abstract}
Aims-To provide practical guidelines for the differentiation between benign and malignant focal lymphoid aggregates (lymphoid nodules) in routinely referred bone marrow trephine biopsies, using a synoptic approach including clinical data and histological workup.

Methods-For easy identification of very small lymphoid infiltrates the chloroacetate esterase stain was applied as a screening procedure. This allowed the identification of 491 formalin fixed, paraffin wax embedded specimens with one or more lymphoid nodules. Examination of lymphoid infiltrates included such variables as histotopography, demarcation, cytology, reticulin fibres, and immunohistochemistry with a set of monoclonal antibodies (CD20, CD45R, CD45R0, CD3, CD43). Evaluation of clinical and morphological data was carried out independently. In case of malignant lymphomas, a correlation with corresponding lymph node findings was made.
\end{abstract}

Results-352 patients had benign focal lymphoid aggregates usually associated with systemic autoimmune diseases, chronic myeloproliferative disorders, toxic myelopathy, and viral infections. Discrete nodular infiltrates of (small cell) malignant lymphomas $(n=93)$ simulating benign hyperplasia were found in chronic lymphocytic leukaemia, germinal centre cell lymphomas (CB-CC), and lymphoplasmacytic/cytoid lymphomas (LPI). In addition to immunoreactivity, certain histological variables proved distinctive. These were: (1) histotopography, that is, localisation of the lymphoid aggregates within the bone marrow space; (2) relation to the surrounding tissue: margination or interstitial spillage of lymphoid cells; and (3) increase in reticulin fibres.

Institute of Pathology, University of Cologne, Joseph-Stelzmann-Str 9, 50924 Cologne,

Germany

J Thiele

T K Zirbes

H M Kvasnicka

R Fischer

Correspondence to: Dr Thiele

email: j.thiele@uni-koeln.de

Accepted for publication 27 November 1998
Keywords: lymphoid nodules; reactive neoplastic lesions; bone marrow; trephine biopsies
There is still a conflict of opinion over the distinction between benign (reactive) focal lymphoid aggregates (nodules, hyperplasia) and infiltrates of malignant lymphomas in bone marrow tissue..$^{1-6}$ This is one of the major continuing problems in haematopathology. In daily routine, the pathologist is frequently confronted by focal lymphoid marrow aggregates of uncertain origin. These lesions may be found in samples derived either from patients with a known lymphoproliferative disorder during a primary or secondary staging procedure, or in specimens with the clinical question of malignant lymphoma, though without appropriate lymph node histology. Moreover, controversy may arise over whether extensive lymphoid nodules accompanying chronic myeloproliferative disorders are only a reactive feature.$^{7-10}$ Finally, many focal lymphoid lesions within the bone marrow lack a relation with an established disorder. In the majority of cases these are associated with the rather ill defined finding of anaemia, particularly in a geriatric population. ${ }^{2-4}$

Our purpose in this study was to investigate systematically the occurrence and relevance of focal lymphoid aggregates in bone marrow trephine biopsy samples retained from routinely referred material. In a synoptic review of the underlying clinical conditions and marrow features, including in particular histotopography, content of reticulin fibres, and immunohistochemistry, we tried to distinguish between benign lymphoid nodules and focal manifestations of malignant lymphomas of the nonHodgkin and Hodgkin type.

\section{Methods}

PATIENTS AND BONE MARROW BIOPSIES

Selection of bone marrow samples included a three step procedure. First, a review of about 18000 representative trephine biopsies drawn from our files and stained by naphthol-AS-Dchloroacetate esterase showed more than 491 specimens with one or several prominent lymphoid aggregates of different size, shape, and cytology. Second, these lymphoid nodules were classified into reactive or neoplastic lesions according to histological appearance and results of immunostaining without knowledge of the patient's identity. Third, the diagnosis was reconsidered in a retrospective analysis of the clinical data. In cases of non-Hodgkin and Hodgkin lymphoma, lymph node pathology and bone marrow findings were compared and correlated with the clinical status. High grade 
Table 1 Monoclonal antibodies according to the CD classification ${ }^{14}$ used in the present study

\begin{tabular}{llll}
\hline Antibody & CD classification & Reacting cell population & Source \\
\hline L26 & CD 20 & B lymphocytes & Dako Diagnostika, Hamburg \\
4 KB5 & CD 45 R & B lymphocytes & Dako Diagnostika, Hamburg \\
LCA & CD 45 & Granulo-lymphocytes & Dako Diagnostika, Hamburg \\
UCHL-1 & CD 45 RO & T lymphocytes and mono-histiocytes & Dako Diagnostika, Hamburg \\
PC3/188A & CD 3 & T lymphocytes and mono-histiocytes & Dako Diagnostika, Hamburg \\
Ki-1 (Ber H2) & CD 30 & Activated lymphoid cells, Reed-Sternberg cells & Dako Diagnostika, Hamburg \\
MT1 & CD 43 & T lymphocytes and myeloid cells & Clonab, Dreieich \\
\hline
\end{tabular}

collaboration was possible because our institution is a lymphoma referral centre. Subtyping of NHL was performed according to the updated Kiel classification. ${ }^{11}$ Patients apparently showing benign focal lymphoid infiltrates were re-evaluated with respect to their underlying condition.

BIOPSY TECHNIQUES AND HISTOLOGICAL PREPARATION

Following a representative trephine biopsy from the posterior iliac crest, fixation was performed in an aldehyde solution for 12 to 24 hours ( $2 \mathrm{ml} \mathrm{25 \%}$ glutaraldehyde, $3 \mathrm{ml} \mathrm{37 \%}$ formaldehyde, $1.58 \mathrm{~g}$ calcium acetate, and distilled water to $100 \mathrm{ml}$ ). Further processing included decalcification for three to four days in $10 \%$ buffered EDTA pH $7.2-7.4$, paraffin embedding, and employment of several staining techniques: Giemsa, PAS (periodic acid Schiff reaction), naphthol-AS-D-chloroacetate esterase, Perl's reaction for iron, and the silver impregnation method after Gomori. ${ }^{12}$

\section{IMMUNOSTAINING}

Pretreatment of mounted paraffin sections included dewaxing through xylene and alcohol and rinsing in buffer ( $50 \mathrm{mM}$ Tris- $\mathrm{HCl}, \mathrm{pH} 7.6)$ for 30 minutes. Thereafter samples were stained according to the alkaline phosphatase-antialkaline phosphatase (APAAP) technique ${ }^{13}$ applying monoclonal antibodies ${ }^{14}$ listed in table 1 in proper concentrations (1:50-100) and variable incubation times (30 minutes to one hour), using new fuchsin as the alkaline phosphatase substrate. To demonstrate monoclonal immunoglobulin expression, the peroxidaseantiperoxidase (PAP) method was applied in combination with polyclonal antibodies, as previously described in more detail. ${ }^{15}$

\section{Results}

The focal lymphoid aggregates found in our bone marrow trephine biopsies varied significantly in frequency, size, localisation, cytological appearance, reticulin fibre content, and immunoreactivity. Features that allowed ready differentiation between benign lymphoid nodules and non-Hodgkin/Hodgkin lymphoma were as follows: first, true lymphoid follicles (fig 1A) with germinal centres cuffing central marrow vessels in 21 patients with an autoimmune disorder (table 2); second, in 46 patients focal accumulations of large blastic (centroblastic-immunoblastic) or polymorphous cells were observed in non-Hodgkin lymphomas of high malignancy; and third, nodular ill defined lesions with increased fibres, vascular proliferation, $\mathrm{T}$ lymphocytes, and plasma cells suggested angioimmunoblas- tic (AILD), while others containing atypical histiocytic cells and mononuclear Hodgkin and Reed-Sternberg cells were consistent with Hodgkin lymphoma (table 3). It should be emphasised that in these cases histopathology was compatible with the diagnosis.

In contrast with those findings, in 93 patients it was difficult to assess solitary or multiple infiltrates (up to eight in one sectional profile) composed of small to intermediate lymphoid cells and simulating benign lymphoid nodules (table 3 ). The procedures that were especially useful in classifying these were histotopography (localisation and infiltration pattern), demarcation, fibre content, and immunostaining. To reach a correct final diagnosis these features should be considered in a synoptic evaluation, as outlined in more detail in table 4 . In this context we should emphasise that every malignant lymphoid infiltrate had a corresponding lymph node diagnosis of lymphoma.

Lymphoid aggregates of reactive origin show a tendency to central localisation and usually have a clearly defined border margin consisting of a mixture of $\mathrm{B}$ and $\mathrm{T}$ lymphocytes (fig 1 , $\mathrm{C}-\mathrm{F})$. A superficial/subcortical infiltrate in the age related adipose tissue or an endosteal tapestry-like (paratrabecular) involvement was not detectable in benign lymphoid nodules, but regularly encountered in CB-CC non-Hodgkin lymphoma (figs $1 \mathrm{~B} ; 2 \mathrm{C}-\mathrm{E}$ ) and also in several cases of lymphoplasmacytic/cytoid (LPI) nonHodgkin lymphoma. An ill defined border of a nodular lymphoid aggregate with spillage of single lymphocytes between the adipocytes or an indian-file-like interstitial extension is often recognised in non-Hodgkin lymphoma (figs $2 \mathrm{~A}, \mathrm{~B} ; 3 \mathrm{~A}, \mathrm{~B})$, but never prominent in reactive hyperplasia. This overspill of lymphocytes into internodular areas is can be shown by applying immunohistochemical methods (figs 2B; $3 \mathrm{~A}$ ). A moderate to pronounced increase in reticulin fibre density within the infiltrates is limited to certain subtypes of non-Hodgkin lymphoma such as CB-CC, LPI (figs $2 \mathrm{~F}, 3 \mathrm{C}$ ), and T cell lymphomas (AILD), in addition to Hodgkin lymphoma. Contrasting with this finding, chronic lymphocytic leukaemia, with a strictly nodular central infiltration pattern, is not characterised by a conspicuous meshwork of reticulin. On the other hand, in HIV myelopathy the inflammatory reaction of the bone marrow stroma is often accompanied by a borderline to moderate increase in fibres. Although the above mentioned indices may be very helpful in distinguishing reactive from neoplastic lymphoid nodules, immunostaining with a set of easy to handle monoclonal antibodies (table 1) presents an invaluable diagnostic tool. This implies first, the demonstration of a uniform 
infiltration pattern consisting of $B$ (or rarely $\mathrm{T}$ ) lymphocytes in accordance with the subtype of NHL (figs 2C-E; 3A,B, D-F); and second, the presence of immunoglobulin light and heavy chain restrictions which proves to be sufficiently reliable to establish monoclonality, as in LPI non-Hodgkin lymphoma (fig 3G, H). For practical purpose a combination of at least two so called $B$ and $T$ cell markers (table 1 ) is advisable, since most monoclonal antibodies show variable cross reactivity with other myeloid cells (figs 2D,E; 3E,F). Relevant features aiding the differentiation between benign lymphoid nodules and non-Hodgkin/ Hodgkin lymphoma are summarised in table 4 .

Finally, when comparing the histological appearance of non-Hodgkin lymphoma in lymph nodes and bone marrow by applying the updated Kiel classification, ${ }^{11}$ in seven cases a discordance was evident. These disparate subtypes included mostly a CB-CC differentiation pattern in the lymph nodes contrasting with a variable fraction of centrocytes versus centroblasts in the bone marrow, or a lymphocytic non-Hodgkin lymphoma in the marrow versus an LPI in the periphery. Several indetermina-

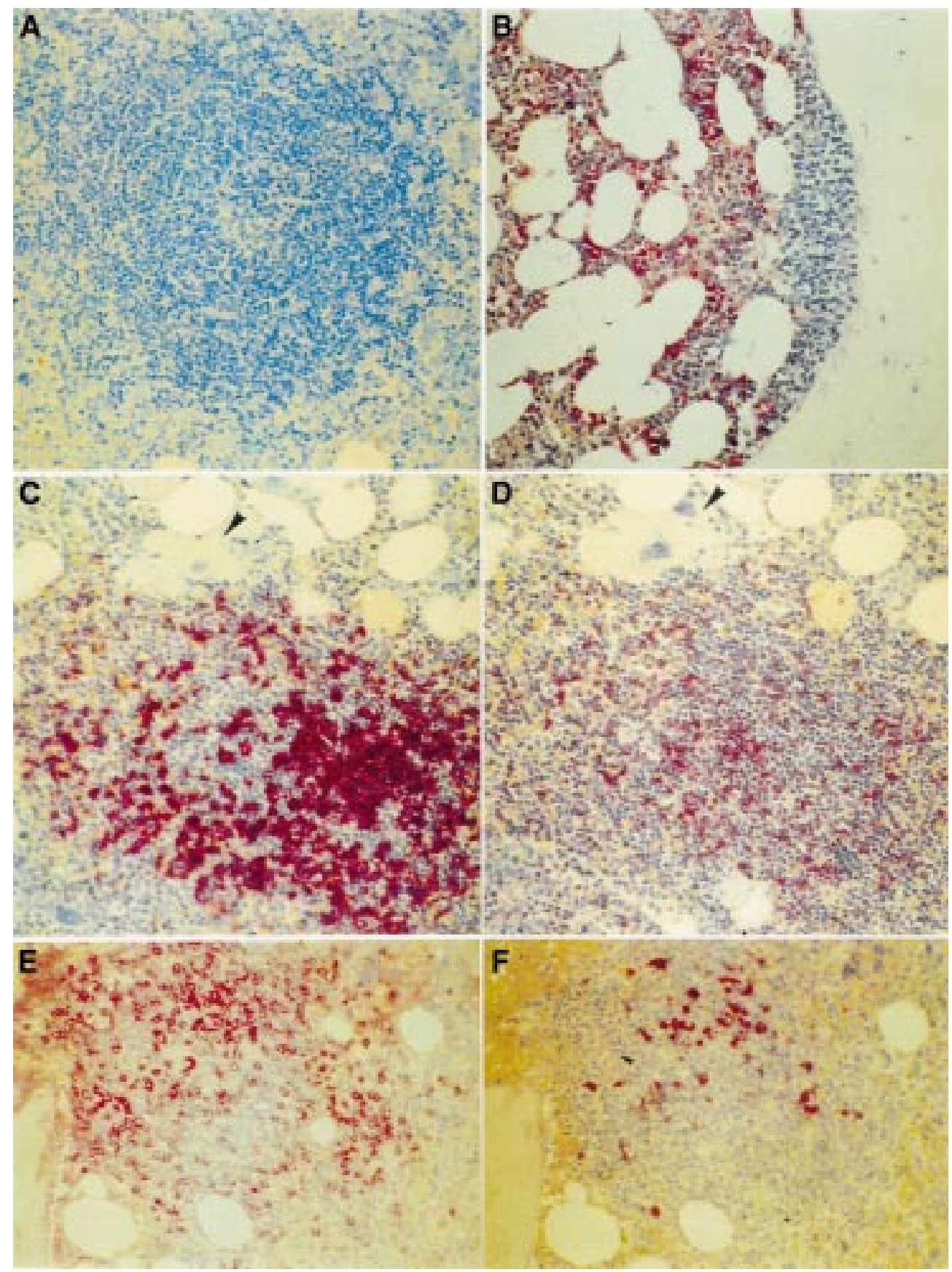

Figure 1 Follicular lymphoid aggregate (true lymphoid follicle) showing a germinal centre in rheumatoid arthritis (A) versus paratrabecular (endosteal) cuffing of malignant lymphoma (germinal centre cell lymphomas (CB-CC)) detected by $A S-D$-chloroacetate esterase staining (B). Immunohistochemistry of benign focal lymphoid infiltrates in idiopathic (primary) myelofibrosis $(C, D)$ showing a mixture of $B(L 26)$ and Tlymphocytes (UCHL-1), in addition to large megakaryocytes (arrowheads). Lymphoid nodule in HIV myelopathy (AIDS) with immunoreactivity revealing a mixture of many $T$ lymphocytes $(E)$ together with a fair number of $B$ lymphocytes $(F)$. (Magnifications: $A \times 175 ; B-F \times 144$.) 
Table 2 Benign lymphoid nodules $(n=352)$ and underlying disorders presenting in about 18000 trephine biopsies of the bone marrow

I. Systemic autoimmune disorders

(a) Rheumatoid arthritis, lupus erythematosus

(b) Autoimmune haemolytic anaemia

(c) Idiopathic thrombocytopenia

(d) Hyper-/hypothyroidism (Hashimoto)

II. Chronic myeloproliferative disorders

(a) Polycythaemia vera

(b) Idiopathic (primary) myelofibrosis

(c) Chronic myeloid leukaemia

(d) Essential (primary) thrombocythaemia

III. Aplastic anaemia (toxic myelopathy)

IV. Myelodysplastic syndromes

V. Viral infections

(a) Hepatitis (B and C type)

(b) HIV myelopathy (AIDS

VI. Unknown or not evaluable

Table 3 Focal bone marrow infiltrates $(n=139)$ in malignant lymphomas: subtypes according to the updated Kiel classification ${ }^{11}$

Lymphocytic (chronic lymphocytic leukaemia, CLL) 29 Centroblastic-centrocytic (CB-CC)

Lymphoplasmacytic/cytoid (LPI)

Centroblastic (CB)

Immunoblastic (IB)

Burkitt type

$\mathrm{T}$ cell lymphoma (angioimmunoblastic, AILD)

Hodgkin lymphoma (HL)

ble cases were also encountered. These included reactive lymphoid accumulations in 17 patients, in whom no relevant underlying disorder could be evaluated. More important, however, were foci of centrally localised (perivascular cuffing) small lymphoid cells displaying $\mathrm{T}$ and $\mathrm{B}$ cell markers in 10 patients following chemotherapy of large cell, highly malignant non-Hodgkin lymphoma (secondary staging procedure). These infiltrates did not correspond with the histological appearance (cytology, histotopography) of the reevaluated primary lesions and were therefore regarded as reactive in nature.

\section{Discussion}

In recent years a wealth of data has accumulated on the clinical importance of making a clear cut distinction between benign lymphoid nodules and focal infiltrations by non-Hodgkin lymphoma $^{5}{ }^{16-22}$ and Hodgkin lymphoma 202123 in the bone marrow. Conventional morphological studies may provide clues to the nature of the lymphoid lesions in those cases, where either large blastic or grossly abnormal cells or a so called packed marrow with an extensive growth pattern are observed. ${ }^{216172122}$ Considerable diagnostic difficulties arise, however, when lymphoid cell involvement is strictly focal and composed of small to intermediate sized elements. Infiltrates of this kind may present early stages of non-Hodgkin lymphoma, especially lymphocytic lymphoma (chronic lymphocytic leukaemia) with a central localisation simulating reactive lesions. In these cases the differentiation has to be unequivocal, because the infiltration pattern of chronic lymphocytic leukaemia has repeatedly been shown to be important in prognosis. ${ }^{1624-28}$

In this study, we have emphasised a synoptic approach to these diagnostic problems, including comparative clinical data and an elaborate histological work up of bone marrow trephine biopsies. Particular interest was focused on the histotopography of lymphoid aggregates in combination with immunohistochemical reactions in providing practical guidelines for diagnosis. However, the method of selection needs to be emphasised, because, in contrast with all other studies where routine staining techniques were applied, ${ }^{1-5} 16-19$ we started with the chloroacetate esterase reaction as the primary screening procedure. This selection criterion for case retrieval was chosen to detect even very small lymphoid infiltrates, in particular those adjacent to the bony trabeculae or generation zone of granulopoiesis which otherwise easily escape recognition. The diagnostic impact of the infiltration pattern also needs emphasis, since it included not only the endosteal localisation that indicated malignancy, ${ }^{256162122}$ but also subcortical involvement of the superficial age related adipose tissue (table 4). In contrast to the well defined and rather discrete outlines of benign lymphoid nodules, fat cells between questionable infiltrates characterised the interstitial spread or spillage of lymphoid cells and therefore suggested non-Hodgkin lymphoma (figs $2 \mathrm{~B} ; 3 \mathrm{C}$ ). These relations between lymphoid nodules and surrounding bone marrow were most impressively demonstrable by applying enzyme (AS-D-chloroacetate esterase) and immunostaining techniques. Although in HIV myelopathy (AIDS), reactive lymphoid aggregates show an increase in finely dispersed fibres, ${ }^{29-31}$ non-Hodgkin lymphomas, with the exception of chronic lymphocytic leukaemia, usually showed a definite tendency to develop a moderate to significant accumulation of reticulin. ${ }^{16}{ }^{32}$

A conflict of opinion has emerged over whether monoclonality is definite proof of malignancy, particularly with respect to corresponding bone marrow lesions. It is not universally accepted that an accumulation of plasma cells with (monotypic) light chain restrictions implies malignancy, because not all monoclonal gammopathies are compatible with malignant myelomas. Moreover, there are

Table 4 Criteria for the differentiation between focal infiltrates of malignant lymphomas and reactive nodular lymphoid hyperplasia

\begin{tabular}{lll}
\hline Variable & Malignant lymphoma & Benign lymphoid aggregate \\
\hline Number of infiltrates in section profile & $\geqslant 1$ without germinal centres & $\leqslant 3$ with partial germinal centres (lymphoid follicles) \\
Histotopography & 1. Paratrabecular-endosteal (except CLL) & 1. Central-perivascular \\
& 2. Subcortical in adipose tissue & 2. Deep marrow spaces \\
Reticulin fibres & 3. Focal-nodular with interstitial spread (indian file pattern) & 3. Fairly defined margin \\
Immunohistochemistry & Moderate to advanced (except CLL) & Borderline to minimal (except HIV myelopathy) \\
& Uniform pattern with predominance of B or T lymphocytes; $\begin{array}{l}\text { Polyclonal pattern with mixture of B and T } \\
\text { lymphocytes; polyclonal expression of }\end{array}$ & immunoglobulins \\
\hline
\end{tabular}


diagnostic problems regarding composite nonHodgkin lymphomas - that is, T-cell-rich B cell lymphomas or an admixture of $\mathrm{T}$ cells in small $\mathrm{B}$ cell lymphomas. In routinely processed bone marrow tissue it may be difficult to demonstrate monoclonality, depending on the methods used, and consequently most studies have used frozen section material. ${ }^{20} 3334$ The processing of bone marrow tissue in this study was restricted to easy to handle and reproducible techniques ${ }^{12}$ without immunohistochemi-
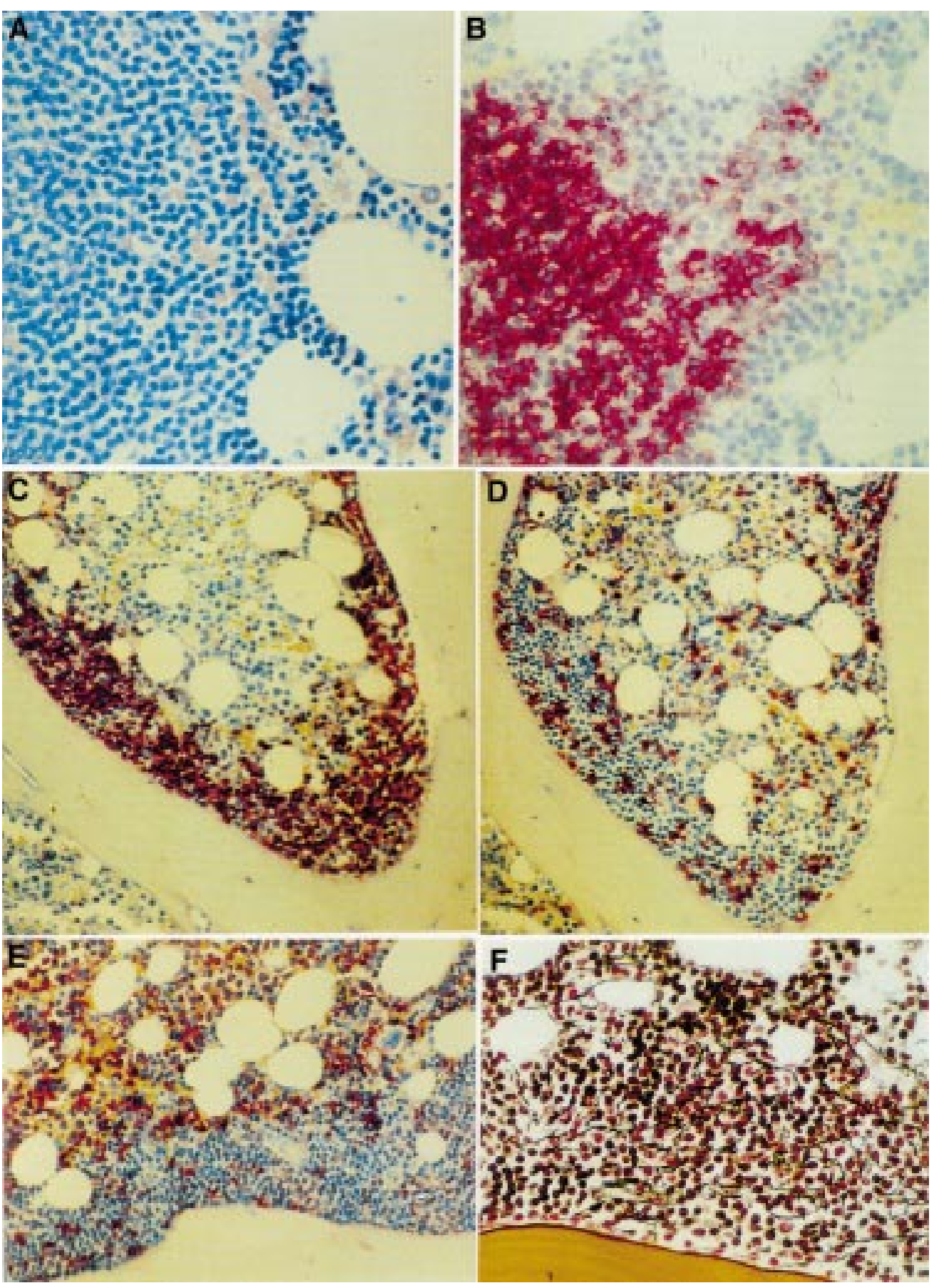

Figure 2 Histotopography and immunohistochemistry of malignant lymphoma infiltrates in the bone marrow. Deficient margination (A) with interstitial lymphoid cell invasion between adipocytes (Giemsa) and conspicuous spillage of $B$ lymphocytes (L26) into the surrounding haematopoiesis in CLL (B). Tapestry-like endosteal localisation of CB-CC lymphoma infiltrates $(C-E)$ revealing an almost uniform expression of $B$ cell markers $(C, L 26)$. Monoclonal antibodies directed against $T$ cells $(D, U C H L-1 ; E, M T 1)$ are either negative or show, in addition to very few residual B lymphocytes, some cross reactivity with a few lymphohistiocytic cells. There is paratrabecular increase in reticulin fibres $(F)$ in these lymphoma infiltrates (CB-CC). (Magnifications: $A, B, F \times 308$; $C, D, E \times 146$.) cal limitations. A comparative study on the different methods of identifying lymphoid lesions cified, and paraffin wax embedd biopsies as opposed to plastic (methyl methacrparticular frozen sections. ${ }^{2}$ By applying a obstacles of cross reactivity (table 1), we succeeded in showing the predominantly uniform expression of a prevailing $\mathrm{B}$ cell or $\mathrm{T}$ cell population composing these lymphoid aggre-

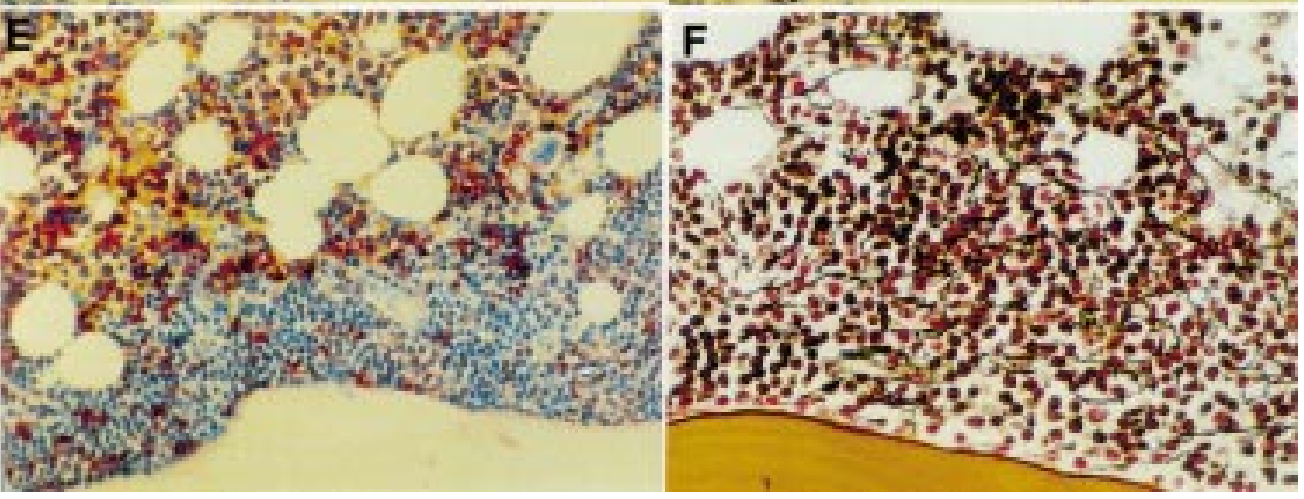


gates in routinely processed bone marrow specimens. This is in keeping with a recently published systematically conducted immunohistological study on paraffin embedded bone marrow biopsies which also included lymphoproliferative disorders. ${ }^{35}$ Although monoclonality may present a major argument for nonHodgkin lymphoma infiltrates versus benign lymphatic hyperplasia, this finding should be always interpreted in the context of the other features that are important in making the diagnosis, as outlined in table 4. Recently, a consistent expression of the bcl-2 protein in all
non-Hodgkin lymphoma infiltrates of the bone marrow was described, while benign lymphoid nodules were claimed to lack this antigen. ${ }^{36}$ However, a critical re-evaluation of this distinctive feature showed the presence of bcl- 2 in both benign as well as malignant lymphoid nodules. ${ }^{37}$ For this reason, the property of bcl-2 for differentiation remains questionable.

Finally, depending on classification, comparative histology of non-Hodgkin lymphoma in lymph nodes and bone marrow showed disturbing discrepancies in several cases and thus confirmed previous studies in this field. ${ }^{38-40}$ In
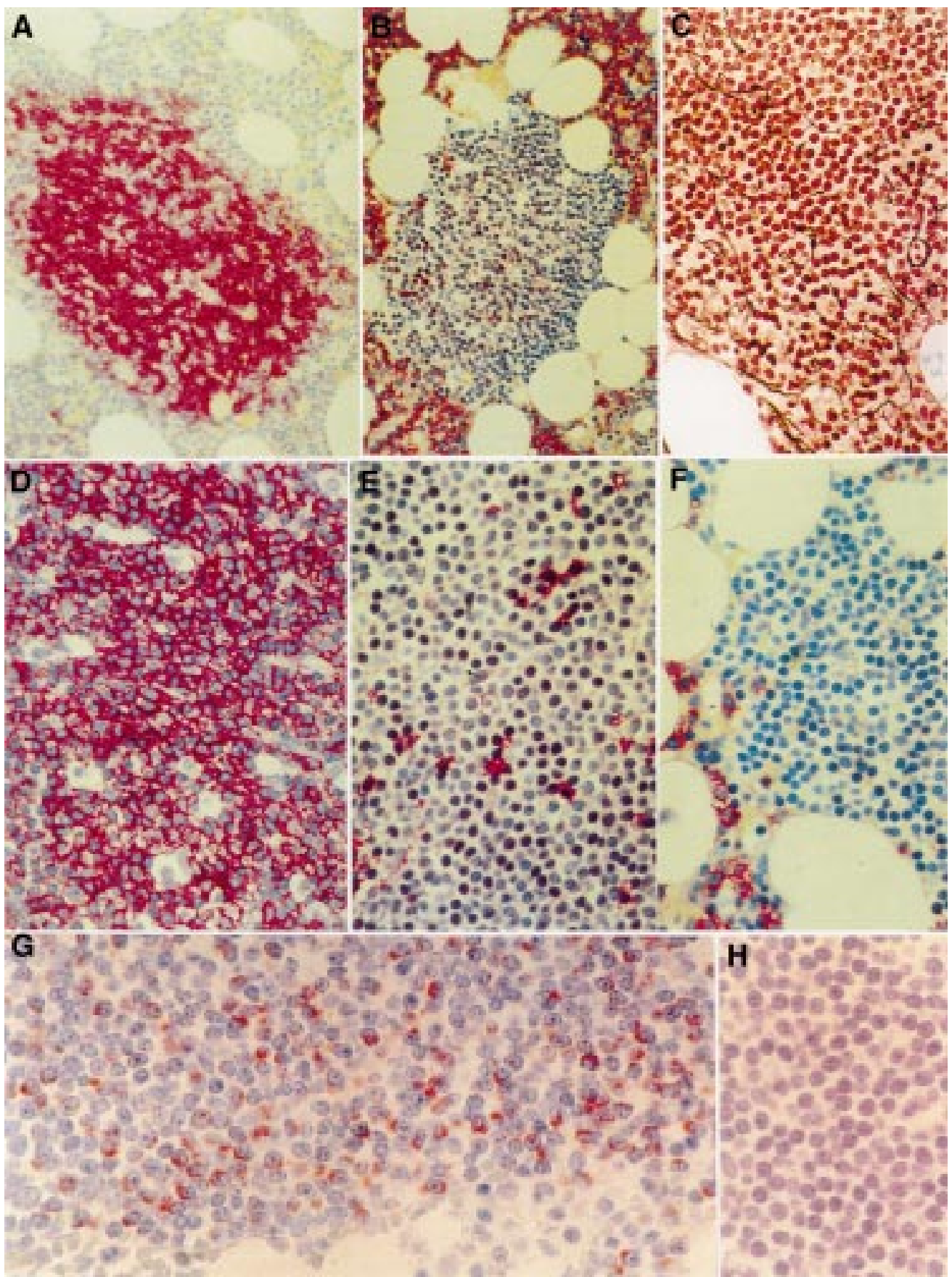

Figure 3 Immunohistochemistry of malignant lymphoma infiltrates (LPI subtype) in the bone marrow $(A, B)$. There is an ill defined margination ( $A, L 26 ; B, M T 1)$ and an increase in reticulin fibres in these lesions (C). Lymphoid nodules consist of B lymphocytes (D, L26), while UCHL-1 (E) shows positive staining of a few lymphohistocytes, and MT1 (F) a negative reaction. Monoclonal expression of light chains of the $\kappa$ type is shown $(G)$, contrasting negativity with an antibody directed against $\lambda$ light chains $(H)$. (Magnifications: $A, B \times 145$; $C-F \times 298$; $G, H \times 467$.) 
particular, a high incidence of morphological discordance was observed with a more aggressive (large cell blastic) nodular subtype, in contrast with the findings in bone marrow. ${ }^{39}$ This aspect probably involves histological progress and transformation, with a change from low to high grade malignancy which may not occur simultaneously and at the same speed in lymph node and bone marrow tissue alike.

In conclusion, a synoptic approach using several distinctive features, particularly histotopography and immunohistochemistry, presents the most promising way to differentiate between reactive and neoplastic lymphoid nodules in the bone marrow.

We are greatly indebted to Mrs B Rosenbach, Mrs M Wonschick, and Mrs P Schmitz for their excellent technical assistance.

1 Rywlin AM, Ortega RS, Dominguez CJ. Lymphoid nodules of bone marrow: normal and abnormal. Blood 1974;43:389-400.

2 Bartl R, Frisch B, Burkhardt R, et al. Lymphoproliferations in the bone marrow: identification and evolution, classification and staging. F Clin Pathol 1984:37:233-54.

3 Navone R, Valpreda M, Pich A. Lymphoid nodules and nodular lymphoid hyperplasia in bone marrow biopsies. Acta Haematol 1985;74:19-22.

4 Faulkner-Jones BE, Howie AJ, Boughton BJ, et al. Lymphoid aggregates in bone marrow: study of eventual Lymphoid aggregates in bone marrow:
outcome. 7 Clin Pathol 1988;41:768-75.

5 McKenna RW, Hernandez JA. Bone marrow in malignant lymphoma. Hematol Oncol Clin North Am 1988;2:617-35.

6 Salisbury JR, Deverell MH, Cookson MJ. Threedimensional reconstruction of benign lymphoid aggregates in bone marrow trephines. F Pathol 1996;178:447-50.

7 Manoharan A, Catovsky D, Clein P, et al. Simultaneous or spontaneous occurrence of lympho- and myeloproliferative disorders: a report of four cases. $\operatorname{Br} \mathcal{F}$ Haematol 1981;48 111-16.

8 Cervantes F, Pereira A, Marti JM, et al. Bone marrow lymphoid nodules in myeloproliferative disorders: association with the non-myelosclerotic phases of idiopathic myelofibrosis and immunological significance. $\mathrm{Br} \neq \mathrm{f}$ Haematol 1988; 70:279-82.

9 Franco V, Florena AM, Aragona F, et al. Immunohistochemical evaluation of bone marrow lymphoid nodules in chronic myeloproliferative disorders. Virchows Arch $A$ chronic myeloproliferative
Pathol Anat 1991;419:261-6.

10 Bartl R, Frisch B, Wilmanns W. Potential of bone marrow biopsy in chronic myeloproliferative disorders (MPD). Eur 7 Haematol 1993:50:41-52.

11 Stansfeld AG, Diebold J, Kapanci Y, et al. Updated Kiel classification for lymphomas. Lancet 1988;i:292-3.

12 Schaefer HE. How to fix, decalcify and stain paraffinembedded bone marrow biopsies. In: Lennert K, Huebne $\mathrm{K}$, eds. Pathology of the bone marrow. Stuttgart: Fischer, 1984:6-9.

13 Cordell JL, Falini B, Erber WN, et al. Immunoenzymatic labelling of monoclonal antibodies using immune complexes of alkaline phosphatase and monoclonal antialkaline phosphatase (APAAP complexes). 7 Histochem Cytochem 1984;32:219-29.

14 Erber WN. Human leucocyte differentiation antigens: review of the CD nomenclature. Pathology 1990;22:61-9.

15 Thiele J, Arenz B, Klein H, et al. Differentiation of plasma cell infiltrates in the bone marrow. A clinicopathological study on 80 patients including immunohistochemistry and study on 80 patients including immunohistochemistry and
morphometry. Virchows Arch A Pathol Anat 1988;412:55362 .

16 Bartl R, Frisch B, Ketter G, et al. Assessment of bone marrow histology in the malignant lymphomas (nonHodgkin's): correlation with clinical factors for diagnosis prognosis, classification, and staging. $\mathrm{Br} f \mathcal{f}$ Haematol 1982;51:511-30

17 Vykoupil KF, Georgii A. Non-Hodgkin's lymphomas in bone marrow: diagnosis according to Kiel classification and their growth patterns and relations to survival. In: Lennert K, Huebner K, eds. Pathology of the bone marrow. Stuttgart: Fischer, 1984:339-46.

18 Foucar F, McKenna RW, Frizzera G, et al. Bone marrow and blood involvement by lymphoma in relationship to the Lukes-Collins classification. Cancer 1982;49:888-97.

19 Bennett JM, Cain KC, Glick JH, et al. The significance of bone marrow involvement in non-Hodgkin's lymphoma: the eastern cooperative oncology group experience. 7 Clin Oncol 1986;4:1462-9.

20 Thaler J, Dietze O, Denz H, et al. Bone marrow diagnosis in lymphoproliferative disorders: comparison of results obtained from conventional histomorphology and immunohistology. Histopathology 1991;18:495-504.

21 Lambertenghi-Deliliers G, Annaloro C, Soligo D, et al. Incidence and histological features of bone marrow involvement in malignant lymphomas. Ann Hematol 1992; 65:61-5.

22 Schmid C, Isaacson PG. Bone marrow trephine biopsy in lymphoproliferative disease. F Clin Pathol 1992;45:745-50.

23 Bartl R, Frisch B, Burkhardt R, et al. Assessment of bone marrow histology in Hodgkin's disease: correlation with clinical factors. Br $\mathcal{F}$ Haematol 1982;51:345-60.

24 Han T, Barcos M, Emrich L, et al. Bone marrow infiltration patterns and their prognostic significance in chronic ymphocytic leukemia: correlations with clinical, immunologic, phenotypic, and cytogenetic data. F Clin Oncol 1984; 2:562-70.

25 Rozman C, Montserrat E, Rodríguez-Fernández JM, et al. Bone marrow histologic pattern - the best single prognostic parameter in chronic lymphocytic leukemia: a multivaritic survival analysis of 329 cases. Blood 1984;64:642-8.

26 Pangalis GA, Roussou PA, Kittas C, et al. B-chronic lymphocytic leukemia. Prognostic implication of bone lymphocytic leukemia. Prognostic implication of bone marrow histology in 120 patients-experience

27 Montserrat E, Rozman C. Bone marrow biopsy in chronic lymphocytic leukemia: a review of its prognostic importance. Blood Cells 1987;12:315-26.

28 Frisch B, Bartl R. Histologic classification and staging of chronic lymphocytic leukemia. A retrospective and pro-
spective study of 503 cases. Acta Haematol 1988;79:14052.

29 Frisch B, Bartl R, Goebel FD. Bone marrow manifestations in the acquired immune deficiency syndrome (AIDS). A study of 40 patients and review of the literature. Hematol Rev 1989;3:177-86.

30 Harris CE, Biggs JC, Concannon AJ, et al. Peripheral blood and bone marrow findings in patients with acquired immune deficiency syndrome. Pathology 1990;22:206-11.

31 Karcher DS, Frost AR. The bone marrow in human immunodeficiency virus (HIV)-related disease. Am $\mathcal{F}$ Clin Pathol 1991;95:63-71

32 Thiele J, Langohr J, Skorupka M, et al. Reticulin fibre content of bone marrow infiltrates of malignant non-Hodgkin's ymphomas (B-cell type, low malignancy) - a morphometric evaluation before and after therapy. Virchows Arch A Pathol Anat 1990;417:485-92.

33 Kronland R, Grogan T, Spier C, et al. Immunotopographic assessment of lymphoid and plasma cell malignancies in the bone marrow. Hum Pathol 1985;16:1247-54.

34 Pizzolo G, Chilosi M, Cetto GL, et al. Immuno-histological analysis of bone marrow involvement in lymphoproliferaanalysis of bone marrow involvement in lymp

35 Pileri SA, Roncador G, Ceccarelli C, et al. Immunohistochemistry of bone marrow biopsy. Leukemia Lymphoma 1997; 26(suppl 1):69-75.

36 Ben-Ezra JM, King BE, Harris AC, et al. Staining for bcl-2 protein helps to distinguish benign from malignant ymphoid aggregates in bone marrow biopsies. Mod Pathol 1994;7:560-64

37 Fakan F, Skálova A, Kuntscherová J. Expression of bcl-2 protein in distinguishing benign from malignant lymphoid aggregates in bone marrow biopsies. Gen Diagn Pathol 1995/96;141:359-63

38 Bartl R, Hansmann ML, Frisch B, et al. Comparative histology of malignant lymphomas in lymph node and bone marrow. Br f Haematol 1988;69:229-37.

39 Conlan MG, Bast M, Armitage JO, et al. Bone marrow involvement by non-Hodgkin's lymphoma: the clinical significance of morphologic discordance between the lymph node and bone marrow. F Clin Oncol 1990;8:1163-72.

40 Kluin PM, van Krieken JH, Kleiverda D, et al. Discordant morphologic characteristics of B-cell lymphomas in bone marrow and lymph node biopsies. Am $\mathcal{F}$ Clin Pathol 1990;94:59-66. 